\title{
(1)

\section{Correction to: Subtitlers' Visibilities on a Spectrum in the Digital Age: A Comparison of Different Chinese Translations of The Big Bang Theory}

\author{
Boyi Huang
}

\section{Correction to:}

Chapter 3 in: R. Desjardins et al. (eds.), When Translation Goes Digital, Palgrave Studies in Translating and Interpreting, https://doi.org/10.1007/978-3-030-51761-8_3

Owing to an oversight on the part of Palgrave the affiliation of author in Chapter 3 was incorrectly published. The chapter has now been updated with the correct affiliation as "B. Huang, School of Applied Language and Intercultural Studies, Dublin City University, Dublin, Ireland"

The updated version of this chapter can be found at: https://doi.org/10.1007/978-3-030-51761-8_3 